\title{
Counselling Psychology: What Future Have For It?
}

\author{
$\operatorname{Suman}^{1 *}$
}

\section{ABSTRACT}

Counseling psychology is a psychological specialty that encompasses research and applied work in several broad domains: counseling process and outcome; supervision and training; career development and counseling; and prevention and health. Some unifying themes among counseling psychologists include a focus on assets and strengths, person-environment interactions, educational and career development, brief interactions, and a focus on intact personalities. Counselling psychology is now becoming a very good career option for future psychology students. This paper suggests many career options in counselling psychology.

Keywords: Counselling, Psychology, Future

Counselling Psychology is a specialty within professional psychology that maintains a focus on facilitating personal and interpersonal functioning across the life span. The specialty pays particular attention to emotional, social, vocational, educational, health-related, developmental, and organizational concerns. The practice of Counselling Psychology encompasses a broad range of culturally-sensitive practices that help people improve their well-being, alleviate distress and maladjustment, resolve crises, and increase their ability to function better in their lives. With its attention to both to normal developmental issues and problems associated with physical, emotional, and mental disorders, the specialization holds a unique perspective in the broader practice-based areas of psychology. Counselling Psychologists serve persons of all ages and cultural backgrounds in both individual and group settings. They also consult regularly with organizations seeking to enhance their effectiveness or the well-being of their members. Interventions used by Counselling Psychologists may be either brief or long-term; they are often problem-specific and goal-directed. These activities are guided by a philosophy that values individual differences and diversity and a focus on prevention, development, and adjustment across the life-span. Counselling Psychologists adhere to the standards and ethics established by the American Psychological Association. Counselling psychologists help people of all ages deal with emotional, social, developmental, and other life concerns. These professionals use a variety of strategies to help people manage behavioural issues, cope with stress, alleviate anxiety and

\footnotetext{
${ }^{1}$ Research Scholar, Rohtak, Jai Bharat High School, Nidana, Jind, Haryana, India *Responding Author

(C) 2016 I Suman; licensee IJIP. This is an Open Access Research distributed under the terms of the Creative Commons Attribution License (http://creativecommons.org/licenses/by/2.0), which permits unrestricted use, distribution, and reproduction in any Medium, provided the original work is properly cited.
} 


\section{Counselling Psychology: What Future Have For It?}

distress, and deal with the issues associated with psychological disorders. Counselling psychology focuses on providing therapeutic treatments to clients who experience a wide variety of symptoms. It is also one of the largest specialty areas within psychology.

The Society of Counselling Psychology describes the field as:

"A psychological specialty that facilitates personal and interpersonal functioning across the life span with a focus on emotional, social, vocational, educational, health-related, developmental and organization."

\section{Counseling as Others See It}

Counseling is a much-misunderstood concept. To the laymen it is an occasion where an expert solves the problems of others. Laymen believe that the expert has ready-made solutions for all the problems of human beings. Most counselors know that this is far from truth.

\section{Guidance and Counseling}

The term guidance denotes explicit directions given by an informed person regarding any subject. An expert in career guidance can impart information regarding different career possibilities. He may also be able to tell us where the careers are open and even the possible openings at the time of consultation. In imparting such information the guidance expert can give pieces of information irrespective of the suitability of the client for the job. However, he has also the option to test the suitability of the client using suitable psychological test. Counselling, on the other hand is more dynamic. It aims at the solution of clients' problems. Counselling is a muchmisunderstood concept.. Counselling is a process between the counsellor and the client in which solutions emerge as a joint venture of the two.

\section{Characteristics of counselling}

1. is expected to be a process.

2. Counselling is usually for normal people with problems.

3. It is essentially a dynamic interaction between the client and the counsellor.

4. Client is expected to be frank and forthright in his approach.

5. It is the duty of the counsellor to keep confidentiality regarding the client.

6. Counsellor is to show warmth and sympathy while listening to the client's problems.

7. Counsellor is expected to be non judgmental and non critical.

8. The relationship between the client and the counsellor is expected to be genuine.

9. Counselling usually works at the level of rapport and not at the level of transference.

10. Client's conscious motives are explored rather than the unconscious motives.

\section{Perspective of Counseling}

The perspective of Counseling may change from counselor to counselor. There are differences in training, clients and settings, and even goals. But the basic perspective of counselling remains 


\section{Counselling Psychology: What Future Have For It?}

the same, through with different emphasis. The best examples are the three different definitions of counseling given by Good (1945), Pepinsky and Pepinsky (1954) and Wrenn (1951). Good defined counseling as the "...individualized and personalized assistance with personal, educational, vocational problems, in which all pertinent facts are studied and analyzed, and a solution is sought, often with the assistance of Specialists, school and community resources, and personal interviews in which the counselee is taught to make his own decisions". According to Pepinsky and Pepinsky, "Counseling is a process involving an interaction between a counselor and a client in a private setting, worth the purpose of helping the client change his/her behavior so that a satisfactory resolution of needs may be obtained". To Wrenn, "Counseling is a dynamic and purposeful relationship between two people in which procedures vary with the nature of students' needs, but in which there is always mutual participation by the counselor and the student with the focus upon self-clarification and self-determination by the student". All these definitions have common base but are different in their emphasis. The difference among the three definitions stems from the fact that they have three different orientations. Hann (1953) identifies one group as the social welfare advocates with ideographic interest. The second group is more medically oriented and the thirds group consists of people with student personnel administration and has great interest in measurement. Along with the differences it is worth noting the commonalties. Common to all these perspectives are the notions that,

a. counseling is aimed at helping people make choices and act on them,

b. counseling is a learning process, and

c. counseling enables personality development

A recent and much accepted definition is:

"Counseling denotes a professional relationship between a trained counselor and client. This relationship is usually person-to-person, although it may sometimes involve more than two people. It is designed to help clients to understand and their self determined goals through meaningful resolution of problems of an emotional or interpersonal nature" (Burks and Stefflre, 1979).

The merit of the definition by Burks and Steffler is that it is sufficiently theoretical and at the same time reasonably operational.

\section{Theory and Practice of Counseling}

Theory and practice should go hand in hand. Many trained counselors initially adhere to the theory while starting their career as counsellor. However, even those who are fanatically tied down to one theory appear to change over time. This is because the client is a human being and he is the link between the theory and practice of the counsellor. Rigid theories, like the Procrustean bed, repel the human psyche. When the man does not fit into the theory the counselor is compelled to change his theory. This is one of the most demanding challenges of counselling. 


\section{Counselling Psychology: What Future Have For It?}

Counselors should keep their minds more receptive and flexible. The psychological concept of individual difference must be understood thoroughly. Individual clients differing in their personalities come with dissimilar problems, goals and aspirations. To believe that all those clients would benefit from one kind of theory is unrealistic. It is useful to know that all the wellknown theories have emerged from the practice of individual counselor's personal experience with counselees. This is why we have different theories and practices. Trying to know these theories as old and new broadens our perspective. But what would be ultimately useful is the one that is carved out from the counselor's experience with the counselees. This is why all textbook writers speak of a 'Personal Theory'.

\section{Current Trends in the Practice of Counseling}

Prospective counselors should be aware of major approaches to counseling so as to enable them to acquire a sound basis for developing their own personal brand of counselling. The current trends in this area can be broadly classified into three approaches. They are:

1. cognitive approaches

2. affective approaches, and

3. behavioral approaches.

It may be observed that the approaches closely parallel the three aspects of personality viz., cognition, affection and conation (i.e. knowing, feeling and doing as given by the ancient Philosophers).

\section{Cognitive Approaches}

As Feorge and Cristiani (1981) have pointed out, in the cognitive approaches, the process of counseling is the curing of unreason by reason; i.e., to help clients eliminate most emotional disturbances by learning to think rationally, to help them get rid of illogical, irrational ideas and attitudes and substitute logical, rational ideas and attitudes. It is believed that this process helps the client to attain rational behavior, happiness, and self-actualization. For example Transactional Analysis (TA) aims at the internal dialogues of individuals, which occurs between the various ego states and the struggles between the real parts of their behavior (whether the same is productive or counter productive) and the behavior of others by identifying which ego state is in power at any given time. TA thus gives the clients information about the various types of transactions that occur among individuals and to help them identify the kinds of behavior in which they are involved. The goal of TA is to help clients review their past decisions and make new decisions about their present behavior. It is assumed that this would change their life direction into developing an autonomous life style characterized by awareness, spontaneity. This, it is believed that would, eliminate a life style characterized by manipulative game - playing a self-defeating neurotic tendencies. 


\section{Counselling Psychology: What Future Have For It?}

Directive teaching is the core in all the cognitive approaches. For example in Rational Emotive Therapy (RET) the counselor takes up an active teaching role to educate clients. The RET counselor makes the client understand that the latter's internationalized sentences are quite illogical and especially the current illogical thinking are self-defeating verbalizations of the client. The success if the counselor lies in bringing illogical thinking forcefully to the client's attention. He must also show to the counselee how these thoughts are maintaining his unhappiness and how a rethinking and maintenance of logically and rationality make him happy and contented. In reality therapy, the meaning of reality and the necessity to act responsibly are taught by the counselor.

\section{Affective Approaches}

As the term suggests the affective approaches in counseling focus their attention to what is going on inside the individual, and particularly what the individual is experiencing at a given time. Client-centered counseling of Rogers is perhaps the most well-defined technique in the affective approaches. It also highlights an issue in counseling; namely, how much responsibility can be placed on the client for his own problem solving?

The 'self-theory' of Rogers also assumes a perspective called 'phenomenology'. According to this perspective, people's 'reality' is that which they perceive. The way to understand individuals is to infer the 'phenomenological field' from their behavior. In other words, the 'internal frame of reference' of the client is used in counseling with the implication that counselors must attempt to perceive client's perceptual worlds as closely as they can. This is known as the empathic skill of the counselor.

Individual client's need to strive for wholeness is the focus in Gestalt therapy and counseling. This school of counseling gives importance to the internal world of the individual. Striving for the gestalt or the wholeness is actually a striving for an integration of thinking, feeling, and behaving. The key concept here is awareness. It is believed that the counselors help the clients work toward a total awareness of his experiences. Gestalt psychologists point out that such awareness permits self-regulation and self-control in the direction of increased integration and creativity.

\section{Behavioral Approaches}

While the dynamically oriented theorists try to understand conscious and unconscious through inference, the behavioral counselors concentrate on objective study of client behavior and the learning process. As the emphasis is primarily on overt behavior, the first emphasis is to discover how the behavior was acquired and how it can be changed. The second emphasis, which is a later addition, is on precondition for behavior change. This approach is characterized by (1) a focus on overt and specified behavior; (2) a precise and well spelt out target behaviors called goals; (3) a formulation of a specific and objective treatment procedure to the problem at hand; and (4) an 


\section{Counselling Psychology: What Future Have For It?}

objective assessment of the outcome of counseling in terms of the degree of approximation to the target behavior.

In the behavioral approaches well defined counseling goals are of central importance. The much talked about counselor-counselee relationship in other approaches is of secondary importance only. The main aim of this relationship to the behaviorist counselor is to facilitate greater understanding of the client's view of the problem. This helps to formulate a more successful behavioral plan for bringing about change in the client's maladaptive behavior to one of adaptive behavior (target behavior).

\section{Personal Theory of Counselling}

Each counselor and psychotherapist must ultimately develop a point of view which is uniquely his or her own. Freud was not a Freudian, Jung not Jungian, and Rogers not a Rogerian. Each of them was himself most fully and completely, while building upon the wisdom of the past. Each practitioner must feel that his counseling practice reflects such individuality. This is the reason why no one text or school is fully adequate, and why we try to exemplify an approach which we have termed 'creative synthesizing'. This approach is not an arrogant attempt to put down predecessors. Ideas are rarely developed in solitary efforts. Usually, they are the results of many years of cumulative cross-fertilization of numerous minds. Isaac Newton is alleged to have said on this point, 'If I have seen further, it is because I have stood on the shoulders of giants'.

\section{What Do Counselling Psychologists Do?}

Many counselling psychologists provide psychotherapy services, but other career paths are also available. Research, teaching, and vocational counselling are just a few of the possible alternatives to psychotherapy. Whether they are working with clients in a hospital setting or counselling students in an academic environment, these psychologists rely on a broad range of psychological theories the therapeutic approaches to help people overcome problems and realize their full potential.

\section{Where Do Counselling Psychologists Work?}

Counselling psychologists work in a variety of locations. Some professionals work in academic settings as professors, psychotherapy providers, and researchers. Others work in hospitals and mental health clinics, often alongside physicians and other mental health professionals including clinical psychologists, social workers, and psychiatric nurses. Still other counselling psychologists are self-employed in independent practice and offer psychotherapy services to individuals, families, and groups. A few other employment settings include private business, military, government agencies, consulting practices, and more. 


\section{Counselling Psychology: What Future Have For It?}

\section{Required Education and Training for Counselling Psychology}

A Ph.D., Speed. or Doctorate in Psychology degree is required to become a counselling psychologist. Some students start by earning a bachelor's degree in a subject such as psychology or social work and then receive a master's degree in counselling or psychology before entering a doctorate program. In other cases, students can bypass the master's program and go straight from their undergraduate degree into a five- or six-year doctoral degree program. A Doctor of Philosophy or Doctor of Psychology degree will typically be offered through a university's psychology department.

\section{Counselling Psychology vs. Clinical Psychology}

Out of all the graduate psychology degrees awarded each year, more than half are in the subfields of clinical or counselling psychology. Counselling psychology shares many commonalities with clinical psychology, but it is also unique in several different ways. Many people are puzzled by the fact that some professional psychologists identify themselves as "counselling" psychologists, while others describe themselves as "clinical" psychologists. Counselling and clinical psychologists often perform similar work as researchers and/or practitioners and may work side by side in any number of settings, including academic institutions, hospitals, community mental health centres, independent practice, and college counselling centres, where they may have overlapping roles and functions. To add to the confusion, the term "clinical" psychology is sometimes used in a generic sense by legislators to refer to psychologists authorized to provide direct services in health care settings, regardless of their training.

The differences between counselling and clinical psychologists are rooted in the history of each specialty, which has influenced the focus and emphasis of the training they receive. Both counselling and clinical psychologists are trained to provide counselling and psychotherapy. In order to understand the traditions and orientation of each specialty, it may be helpful to consider the etymology of each of the descriptive terms. Clinical derives from the Greek, "Kline," which means bed, (and is also found in the root of the word "recline"). Clinical practice has traditionally referred to care provided at the bedside of an ill patient. Counsel is from the Latin, "consul ere," which means to consult, advice, or deliberate. These differences, broadly speaking, reflect the earliest focus of each field. Clinical psychologists have traditionally studied disturbances in mental health, while counselling psychologists' earliest role was to provide vocational guidance and advice. Today, though, the differences between psychologists from each specialty are more nuanced, and there are perhaps more similarities than differences among individual psychologists from each field.

The specialties of counselling and clinical psychology evolved concurrently, and at times, their paths of development intertwined. At the end of the 19th century and the beginning of the 20th, psychologists began to seek ways to apply the findings of psychological science to the problems 


\section{Counselling Psychology: What Future Have For It?}

people experience in the world, in areas such as learning disabilities or mental illness. These first psychological clinics offered assessment and treatment services. Later, "clinical psychologists" began to provide psychotherapy, which previously had been the exclusive domain of psychiatrists. At the same time, as society became increasingly industrialized, the vocational guidance movement began to offer assistance to those seeking careers in which they would be most successful (and to provide employers with the most productive employees).

\section{Counselling Psychology Employment}

Counselling Psychologists are employed in a variety of settings depending on the services they provide and the client populations they serve. Although some are employed in colleges and universities as teachers, supervisors, researchers, most have jobs as clinical practitioners (often in independent practice) providing counselling, psychotherapy, assessment, and consultation services to individuals, families, groups, and organizations. Such services may be offered at mental health centres, Veterans Administration Medical Centres and other health care facilities, family services, health maintenance organizations, rehabilitation agencies, business and industrial organizations and consulting firms, as well as through independent practice offices.

\section{Ethics}

Ethics, which are the suggested standards of conduct based on a set of professional values and moral decision making regarding professional behaviour, are usually established by a discipline's professional organization. Counselling professional associations, like the American Counselling Association and the American Psychological Association, have their own code of ethics. These codes do not provide all the answers but do provide information on the most common issues and provide some uniformity between practitioners. Having a code of ethics is not a guarantee that the individual practitioner will follow them. However, it is expected that members of an organization do adhere to the code of ethics. Let's take a look at several important points that will usually be covered in a code of ethics.

\section{Confidentiality}

Confidentiality is an ethical understanding between the counsellor and the client that what the client tells the counsellor will be protected from disclosure without the client's permission. Before counselling sessions begin, the counsellor has the responsibility to inform the client of when they can and when they cannot maintain confidentiality. The client should sign an informed consent form that states that he or she is aware that there are specific times the counsellor cannot maintain confidentiality, such as when the client is a danger to himself or others or when the counsellor is subpoenaed to court.

Licensed private practice counsellors are protected with privileged communication from having to reveal information in court in many cases. The limits of privileged communication will vary by state. Non-licensed counsellors, like school counsellors, do not have this protection in most 


\section{Counselling Psychology: What Future Have For It?}

states. In cases where the counsellor has to reveal information the client has shared with them, the counsellor should reveal as little as possible. The counsellor should err on the side of keeping the confidentiality. If the counsellor reveals information that is not necessary, they leave themselves open to ethical and legal sanctions, including loss of certification and licensure or a malpractice suit.

\section{Exceeding Competence}

Counsellors have an ethical responsibility to present their qualifications and experience truthfully. Many malpractice lawsuits are due to incompetence on the part of the counsellor due to the counsellor presenting herself as more qualified than she is or using techniques in counselling in which she has not had sufficient training. To prevent issues, counsellors who have an area of specialization, such as substance- abuse counselling, or who wish to use specialized techniques usually either take additional coursework in that area or attend conferences and workshops to acquire additional experience.

\section{Sexual and Dual Relationships}

Counsellors should never engage in a sexual relationship with a client - EVER. The greatest number of malpractice suits and complaints to professional organizations involve clientcounsellor sexual relationships. The counsellor is in a position of power over the client by virtue of the position. This means it is always the counsellor's responsibility to prevent these relationships. A counsellor who has sexual feelings for a client may need to refer the client. Ethical standards even suggest that the counsellor should not engage in a sexual relationship with a former client because of that earlier relationship.

What about friendships or other relationships with clients? There is no clear-cut ethical guideline about counselling people that you already have some relationship with. However, the counsellor should use caution in counselling individuals with whom he or she has other relationships, such as family members, friends, and co-workers. The other relationship with the client might impair the counsellor's judgment and objectivity, and may affect the ability to provide services. The counsellor will need to decide if the relationship can cause harm to the client. The counsellor may decide to refer the client to another counsellor or see the client but establish guidelines to prevent ethical issues.

\section{Counter transference}

Another ethical issue that is rarely discussed is counter transference. Counter transference is where the counsellor projects feelings and attitudes that distort the way he or she perceives a client. Perceptions of a client are influenced by the counsellor's own past experiences. Counter transference may result in the counsellor being overprotective, treating the client too cautiously, seeing herself in the client, developing romantic or sexual feelings for the client, giving advice instead of therapy, or developing a social relationship with the client. 


\section{Counselling Psychology: What Future Have For It?}

Counter transference is not all bad and may make the counsellor feel more empathetic of the client and more aware of their own feelings. When it becomes problematic, though, the counsellor should deal with feelings through consultation, supervision, or personal therapy.

\section{Financial Issues}

Counsellors in private practice will have to set fees for their services. They must generate enough income to cover salaries and other business expenses. However, if fees are too high, clients will go elsewhere. If fees are too low, the clients may feel the counsellor must not be as good as others who charge more.

The ACA Code of Ethics states that counsellors should consider the financial status of clients and locality. If the counsellor charges fees that a potential client cannot pay, they must help the client find comparable services with another counsellor.

\section{Rehabilitation}

People and their problems is complex. Therefore, it should come as no surprise that there are various rehabilitation program types, styles and treatment philosophies. What works for one person may not be as effective for another person. Part of that relates to the relatively new concepts of holistic treatment. Those concepts take into account other mental and physical ailments that need to be addressed and treated in order for rehabilitation to be successful not just in the present but also over the long term.

For example, successful rehab for alcoholism may require treating Dual Diagnosis conditions, such as addiction that occurs alongside depression or another mental health disorder. Treatment philosophies can differ between rehabilitation programs, with some stressing cognitive therapies over pharmaceutical treatments, whereas others may weight their treatment plans more towards behavioural modification in highly structured circumstances. Some rehab programs utilize multiple approaches, adjusting the balance and focus of these approaches as treatment progresses.

\section{Change with Time}

After getting the license, it does mean that the education of a counsellor is complete. Our society is changing day by day. The needs and problems of the present society is different from past. So

a counsellor should upgrade himself according to the present need of the society. Daily new theories come in existence. He should have a keen knowledge of them.

\section{Acknowledgments}

The author appreciates all those who participated in the study and helped to facilitate the research process. 


\section{Counselling Psychology: What Future Have For It?}

\section{Conflict of Interests}

The author declared no conflict of interests.

\section{REFERENCES}

Betz, N. (2008). Advances in vocational theories. In: Brown, S.D. \& Lent, R.W. Handbook of Counseling Psychology (4th ed). New York: Wiley

Carkuff, R. (1969). Helping and Human Relations. New York: Holt, Rinehart and Winston.

Constantine, M. \& Sue, D. (2007). Perceptions of racial micro-aggression among black clients in cross-racial studies. Journal of Counseling Psychology, 54(2), 142-153.

Dawis, R. V. \& Lofquist, L.H. (1984). A Psychological Theory of Work Adjustment: An Individual-Differences Model and its Applications. Minneapolis, MN: University of Minnesota Press.

Dillon, F., Worthington, R., Soth-McNett, A., \& Schwartz, S. (2008). Gender and sexual identity-based predictors of lesbian, gay, and bisexual affirmative counseling selfefficacy. Professional Psychology: Research and Practice, 39(3), 353-360.

Egan, G. (2010). The Skilled Helper (9th ed.). Belmont, CA: Brooks Cole, Cengage Learning.

Frisch, M., Cornell, J., Villanueva, M., \& Retzlaff, P. (1992). Clinical validation of the Quality of Life Inventory. A measure of life satisfaction for use in treatment planning and outcome assessment. Psychological Assessment, 4(1), 92-101.

Hill, C.E. \& Lent, R. (2006). A narrative and meta-analytic review of helping skills training: time to revive a dormant area of inquiry. Psychotherapy: Theory, Research, Practice, Training, 43(2), 154-172

Hill, C.E. (2014). Helping Skills (4th ed.). Washington, D.C.: American Psychological Association.

Israel, T., Gorcheva, R., Walther, W., Sulzner, J., \& Cohen, J. (2008). Therapists' helpful and unhelpful situations with LGBT clients: An exploratory study. Professional Psychology: Research and Practice, 39(3), 361-368.

Ivey, A. (1971). Microcounseling: Innovations in Interviewing Training. Springfield, IL: Thomas.

Kagan, N., Krathwohl, D., and Farquhar, W. (1965). IPR-Interpersonal Process Recall. East Lansing, MI: Michigan State University.

Ladany, N. \& Inman, A. (2008) Developments in counseling skills training and supervision. In: Brown, S.D. \& Lent, R.W. Handbook of Counseling Psychology (4th ed.). John Wiley \& Sons: New York.

Lambert, M.J., Gregerson, A.T., \& Burlingame, G.M. (2004). The Outcome Questionnaire-45. In M. Maruish (Ed.). Use of Psychological Testing for Treatment Planning and Outcomes Assessment (3rd ed) (pp. 191-234). Mahwah, NJ: Lawrence Erlbaum Associates.

Norcross, J., Sayette, M., \& Mayne, T. (2008) Insider's Guide to Graduate Programs in Clinical and Counseling Psychology. Guilford Press. 


\section{Counselling Psychology: What Future Have For It?}

Nutt, R.L. \& Brooks, G.R. (2008). Psychology of gender. In: Brown, S.D. \& Lent, R.W. Handbook of Counseling Psychology (4th ed) (pp. 267-283). New York: Wiley.

Westefeld, J.S. (2009). Supervision of psychotherapy: models, issues, and recommendations. The Counseling Psychologist, 37, 296-316.

Whiston, S.C. \& Rahardja, D. (2008). Vocational counseling process and outcome. In: Brown, S.D. \& Lent, R.W. Handbook of Counseling Psychology (4th ed). New York: Wiley.

How to cite this article: Suman (2016), Counselling Psychology: What Future Have For It?, International Journal of Indian Psychology, Volume 3, Issue 4, No. 60, ISSN 2348-5396 (e), ISSN: 2349-3429 (p), DIP: 18.01.080/20160304, ISBN: 978-1-365-26308-8 